\title{
Underserved: A Three-Tiered Approach for Student Social and Emotional Learning Needs
}

\author{
Marie Byrd, EdD \\ Associate Professor \\ University of South Florida Sarasota-Manatee \\ United States \\ Rachel Nez \\ University of South Florida \\ United States
}

\begin{abstract}
The interplay between social/emotional health and student academic success necessitates collaborative partnerships focused on sustainable educational initiatives to meet the needs of the whole child. The most effective approach allows for wide-ranging implementation of Social Emotional Learning (SEL) programs and practices through federal, state and local alliances directed at skill development for school-aged youth. Upon the review of previous and current federal and state efforts, a research-based model consisting of a three-tiered system of wide-ranging implementation of SEL programs and practices is introduced.
\end{abstract}

Key terms: social emotional learning, mental health, educational policy

\section{Introduction}

Current national and state policies affecting public schools center on reducing the academic achievement gap and thus increasing academic performance on standardized testing among subgroups of lower performing U.S. public school students (Musu-Gillette et. al., 2017). However, the U.S. Surgeon General has reported that one in five children and adolescents will face a significant mental health condition during the years in school(NASSP, 2019). Today's schoolaged children are experiencing record levels of depression and anxiety, alongside multiple forms of trauma (ACLU, 2019). According to the Centers for Disease Control (CDC, 2017), the suicide rate among children ages 10 to 17 increased by 70 percent between 2006 and 2016. Failure to adequately address the underserved population of students diagnosed with social/emotional and mental health issues may result in secondary trauma or even post-traumatic stress syndrome (PTSD) that can lead to the inability to focus, poor school performance, substance abuse, inflicting abuse on self, bullying, and additional school violence (WVDE, 2014).

The interplay between social/emotional health and student academic success necessitates collaborative partnerships focused on sustainable educational policy and/or initiatives to meet the needs of the whole child. The most effective approach allows for wide-ranging implementation of social emotional learning (SEL) programs and practices through federal, state and local alliances directed at social and emotional skill development for school-aged youth. Upon the review of previous and current federal and state efforts, a research-based model of a three-tiered system of wideranging implementation of SEL programs and practices is introduced.

\section{Background of Student Mental, Social and Emotional Health and Related Policy}

In 2009 it was estimated that ten percent of children and adolescents in the United States suffer from mental illness to the point of impairment, yet only one fifth of those receive any type of treatment (Toma, 2009). A 2017 report on behalf of the Milbank Memorial Fund revealed nearly one in seven children aged 2 to 8 years in the United States had a mental, behavioral, or developmental disorder. Among children and adolescents aged 9 to 17 years, as many as one in five may havea diagnosable psychiatric disorder (Tyler, Hulkower, \&Kaminski, 2017). With significant barriers to accessing specialty care, primary care pediatricians are often tasked with identifying and managing behavioral health needs while reporting an inability to find specialty services for their patients (Tyler, Hulkower, \& Kaminski, 2017). It has also become apparent that teachers are not well equipped with the knowledge of research-based best practices in mental, social and emotional skill building (Toma, 2009). Early access to mental and social/emotional health services, whether in schools, after school programs, or through direct service providers, builds resiliency in children and adolescents (Nelson, Leone, \& Rutherford, 2004). 
In 1999, the Safe School/Healthy Students initiative, an incentive-based program, granted money to school districts that adopted its initiative to reduce risk factors and support resilience (Furlong, Paige, \& Osher, 2003). The initiative encouraged connecting children with caring adults, implementing positive behavioral support systems, increasing the focus on social and emotional skills, and providing early intensive interventions. Emphasis was placed on school psychologists that are equipped with not only the psychological background, but knowledge of the school environment, climate, and overall inner workings of a school. Through this increased focus, teachers and students reported a positive impact (Furlong, Paige, \& Osher, 2003).

In 2002, President George W. Bush created the President's New Freedom Commission on Mental Health, bringing focus on the need to increase mental health programs in schools. As a part of this executive order, early mental health screenings were made a priority with a clear understanding that the realities of a child's daily life leaves two entities capable of preventing, recognizing and intervening: parents/family, or teachers/schools (Toma, 2009).

The primary focus of the Every Student Succeeds Act (ESSA) of 2015 is that of preparing students for college and/or careers upon graduation from high school (USDOE, 2015), without a specified emphasis on the social and emotional competencies for success in college and/or careers. Even with the recent increased focus on how the United States' educational system may implement social and emotional learning (SEL) and shift from high-stakes test-based accountability, proactive approaches from the federal and state level are limited and few. The Association for Supervision and Curriculum Development (ASCD, 2019) developed a list of programs where potential funding for Social Emotional Learning may be available under ESSA. The brief list was comprised of sections where the justification for allowable uses of funding for SEL through ESSA. This analysis included sections of ESSA where the language of the statute allows for activities or personnel expenditures for which funding may be diverted to support SEL.

While emotional and behavioral disorders (EBD) are under the umbrella of IDEA, other mental health concerns are not, (Golembiewski, 2016). When EBD is external, it is more likely to be identified for special education services (Marsh, 2016). Students who have more internal EBD are less likely to be identified for mental health services (Forness et al., 2012; Mental Health America 2015). "It is critical that we address the differential treatment of students with mental health disabilities under the IDEA. The legal protections and resources offered by the IDEA, combined with the unique position of schools in children' slives, present an opportunity to identify mental health disabilities earlier and address them more effectively." (Golembiewski, 2016, p. 475). If interpreted more openly, IDEAcould open the doors for requiring and providing the interventions and services needed for students to regain mental wellness (Golembiewski, 2016).

School counselors have reported that though they know it is part of their job to address student social, emotional and mental health, they feel a lack of time and resources inhibits them to help students with mental health needs (DeKruyf, Auger \& Trice-Black, 2013).Students that do receive referrals to experience delays in services as once the referral is given, there are many limiting factors as to whether or not the student ends up receiving the services referred (Marsh, Morgan, Higgins, Lark \&Watts, 2017).The recommended counselor to student ratio is 250:1; yet many schools in the United States are over 471:1 with research indicating that schools with lower counselor to student ratios had fewer disciplinary behavioral incidences and an improved overall school climate (DeKruyf, Auger \& Trice-Black, 2013).

\section{A 3-Tiered Analysis of Student SEL}

\subsection{Federal Policy}

In the fall of 2018, the U.S. Departments of Education, Justice, Homeland Security, and Health and Human Services convened the federal commission on school safety to develop a report of examples, adaptations and resources with the purpose of advancing safety in American schools. However, the document contained a disclaimer indicating mandated or prescribed practices were not included and no force of law or additional requirements were authorized beyond those included in applicable laws and regulations. The final report was organized into three broad categories of:1) prevent; 2) protect and mitigate; and 3) respond and recover(Federal Commission on School Safety, 2018). The report emphasized the voluntary nature of the practices identified with language implying that the guide was "...purely voluntary, and no federal agency will take any action against schools that do not adopt them" (Federal Commission on School Safety, 2018, p. 2). While well intended, the report did little to advance policy action on the status of student mental health.

Policy action has been promoted by the National Association of Secondary School Principals (NAASP) within position statements that promote student mental health as a critical component of improving school climate, safety, and learning (NASSP, 2018). Those recommendations include specifications for financial support at the federal level that provide the impetus for state legislatures and local school districts to implement changes. Below are a selected few of the NASSP (2018) policy recommendations that have been edited to include student social and emotional learning. 
- Financial support to enable local communities to implement a comprehensive culturally and linguistically appropriate school-based mental health program focused on Social and Emotional Learning (SEL);

- Funding to enable schools to lower the counselor-to-student ratio to levels recommended by the American School Counselor Association, in support of providing counselors greater opportunity to service students with SEL; and

- Funding for recruiting and retaining school counselors, school social workers, school psychologists, and mental health specialists to support school-based interventions and the coordination of SEL services

\subsection{State Policy}

The plethora of state level policies on school safety and security have been documented by the Education Commission of the States (ECS). On behalf of the ECS, Macdonald \& Perez (2019) researched K-12 school safety policies in all 50 states and the District of Columbia. It was found that at least 43 states and the District of Columbia require a school safety plan in statute or regulation. Also, at least 42 states require schools to conduct safety or security drills in state statute or regulation. There is also further data regarding state policies for school resource officers and carry permits for weapons and involvement of law enforcement (https://www.ecs.org/50-state-comparison-k-12-school-safety/).

The paucity of state policies on student SEL and/or mental health isapparent. The Education Commission of the States (ECS) conducted a scan of enacted legislation from the 2013 legislative sessions to capture the ongoing work of lawmakers on student mental health. Of the scan, 17 bills from 13 states illustrated the large range of mental healthrelated legislation passed (ECS, 2014):

- Requirements for mental health training for teachers, administrators or other school staff were enacted in Connecticut, Maine, North Dakota, Texas and Washington.

- California, Minnesota and Utah passed requirements for mental health education for students or parents.

- Minnesota extended the allowable uses of an existing funding stream to include paying for mental health professionals.

- California passed a law requiring the education department to post links to mental health resources on its website.

- Oregon passed a bill allowing students or parents to opt out of mental health screenings.

In 2018, state policy action on mental health centered on four main areas (ECS, 2018): 1) providing for school based mental health professionals; 2) creating greater awareness of mental health issues through curriculum and staff training; 3)introducing trauma informed practices; and 4) incorporating social and emotional learning. Eleven states engaged in this work by increasing funding through state grants and private foundation funds. Only Virginia and New York have recently addressed social emotional learning (SEL) into their state education standards by requiring mental health education curriculum (https://www.ecs.org/state-legislation-by-state). Colorado's Comprehensive Health Education Standards includes sections on emotional and social wellness (ECS, 2018). Washington developed health and physical education standards that include social and emotional learning, and connect the concept to several risk factors, including bullying, stress management and body image (ECS, 2018).

Through targeted federal financial support authorizing the implementation of state-selected mental health curriculum for $\mathrm{K}-12$, states may gain the stimulus needed to focus on curriculum outside of the tested subjects. In addition to curriculum, state-wide mental health screening and reporting systems are needed to host the records of all required mental health screenings. Avenues for students, parents, teachers and administrators to report mental health concerns would assist with the school district's ability to provided support services. Further suggestions for the state role are indicated below within selected state policy recommendations (NASSP, 2018) that have been expanded to provide a focus on student SEL.

- States should facilitate community partnerships among families, students, education systems, mental health service systems, family-based mental health service systems, government agencies, health care service systems, and other community-based systems to provide emphasis on student SEL.

- State policymakers should provide funding to support the hiring of mental health specialists that have specific SEL training to serve students and schools.

- States should provide funding to increase SEL professional development opportunities for school administrators, teachers and other school staff.

\subsection{Local Policy}

Funding and support from the state level may boost local school district efforts to provide continuous systemic professional development on student SEL as a part of state mental health curriculums for administrators, teachers and related school personnel. State funding also allows school districts to provide mental health professionals with appropriate ratios for each districted school. 
A research-based and systemic local approach is the Framework for Social and Emotional Learning from the Collaborative for Academic, Social, and Emotional Learning (CASEL, 2019). It outlines a structure for local school districts' adoption of a systemic framework of five core competencies that encompasses multiple settings. With the synchronicity of appropriate systems, reported information is therefore aligned so that the child's SEL needs are met in a multitude of settings. CASEL's framework classifies five core competencies that provide for assimilation across multiple settings: 1) Self-awareness; 2) Self-management; 3) Social awareness; 4) Relationship skills; and 5) Responsible decision-making (CASEL, 2019). The five core competencies, when prioritized with appropriate emphasis by local school districts across settings to include schools and classrooms, families, community agencies, the juvenile justice system and the wider community, may effectively provide the child-centered network required to support the social and emotional needs of students (see Figure 1).

Figure 1: Framework for Social Emotional Learning

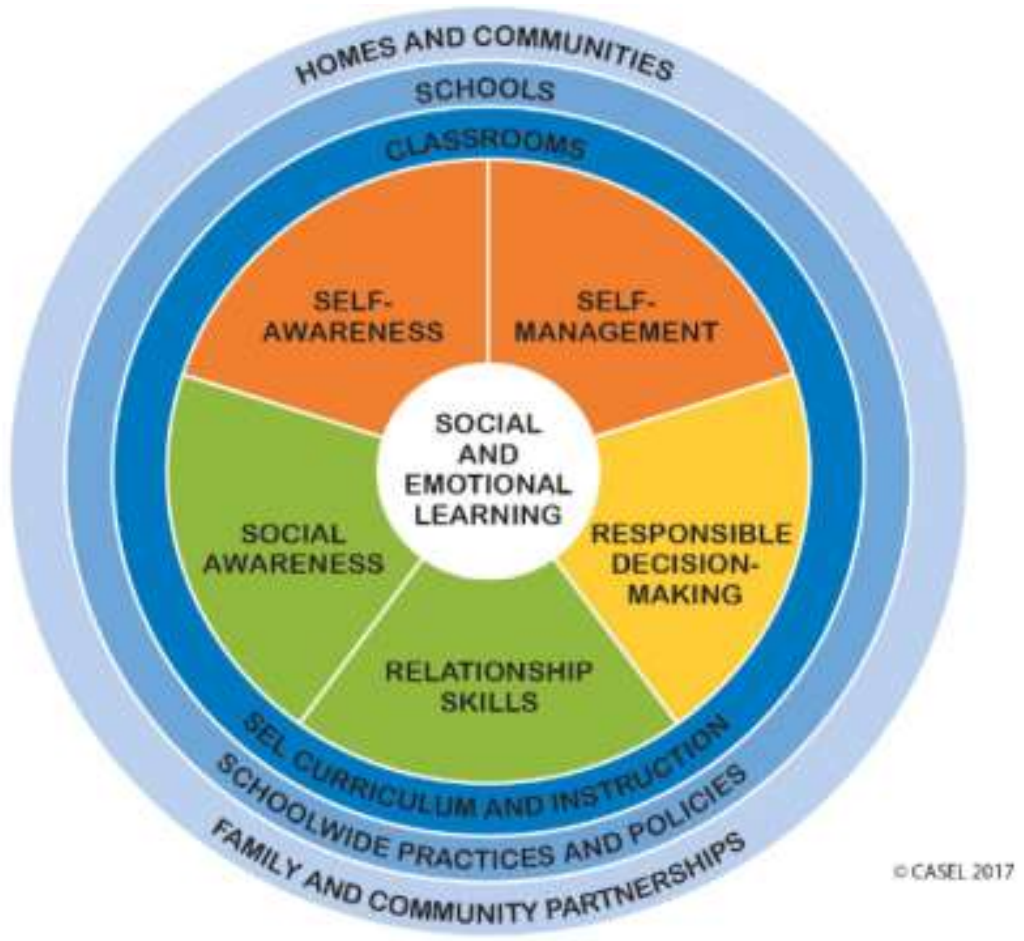

https://casel.org/core-competencies/

In addition to local school districts' adoption of a systemic framework of the five core CASEL competencies that encompasses multiple settings, selected local school district policy suggestions from NASSP (2018) is also of importance. The NASSP suggestions, expanded to include the focus on student SEL are 1) School and district leaders should maintain ongoing staff development regarding student SEL issues; and 2) School and district leaders should establish curricula for grades K-12 that address SEL, bullying and violence prevention, including electronic aggression.

\section{SEL Three-Tiered Model}

Educational restructuring is unlikely without the adoption of new policy initiatives at each level (Spillane, 1998). The recommended federal approach to state and local policy action regarding student SEL is that of a competitive grant process similar to the Race to the Top initiative(https://www2.ed.gov/programs/racetothetop/index.html), the $\$ 4$ billion program in 2010 as part of the American Recovery and Reinvestment Act (ARRA). The federal initiative provided monetary incentives for states to establish requested changes in the schools. The competitive grant program "encouraged broad-based, systemic educational improvements even in states that did not win Race to the Top funding" (USDOE, 2015, p.vii). Findings from a study (Howell, 2015) indicated that Race to the Top had a significant influence on the increase of education policy across the United States. States experienced a noticeable increase in the adoption of education policies as legislators from all states reporting that Race to the Top affected policy negotiations within their states (Howell, 2015). 
In alignment to the 2010 initiative, the federal role will be to empower each state to financially support comprehensive statewide educational improvements in the social and emotional learning of K-12 students. The competitive grant may be awarded based on each state's plan to:

- adopt state-wide student mental health curriculum addressing SEL;

- provide funding and support for school districts to for recruit and retain school counselors, school social workers, school psychologists, and mental health specialists to support school-based interventions and the coordination of SEL services; and

- provide for ongoing staff development regarding student SEL issues for school site administrators, teachers and staff.

The interplay between social/emotional health and school success necessitates collaborative partnerships between mental health professionals and educators to meet the academic, social and emotional needs of an underserved student population. The most effective approach encompasses a multi-tiered system of federal policy makers, state government and local school districts that allow for wide-ranging implementation of SEL programs and practices (see Figure 2).

Figure 2: SEL Three-Tiered Model

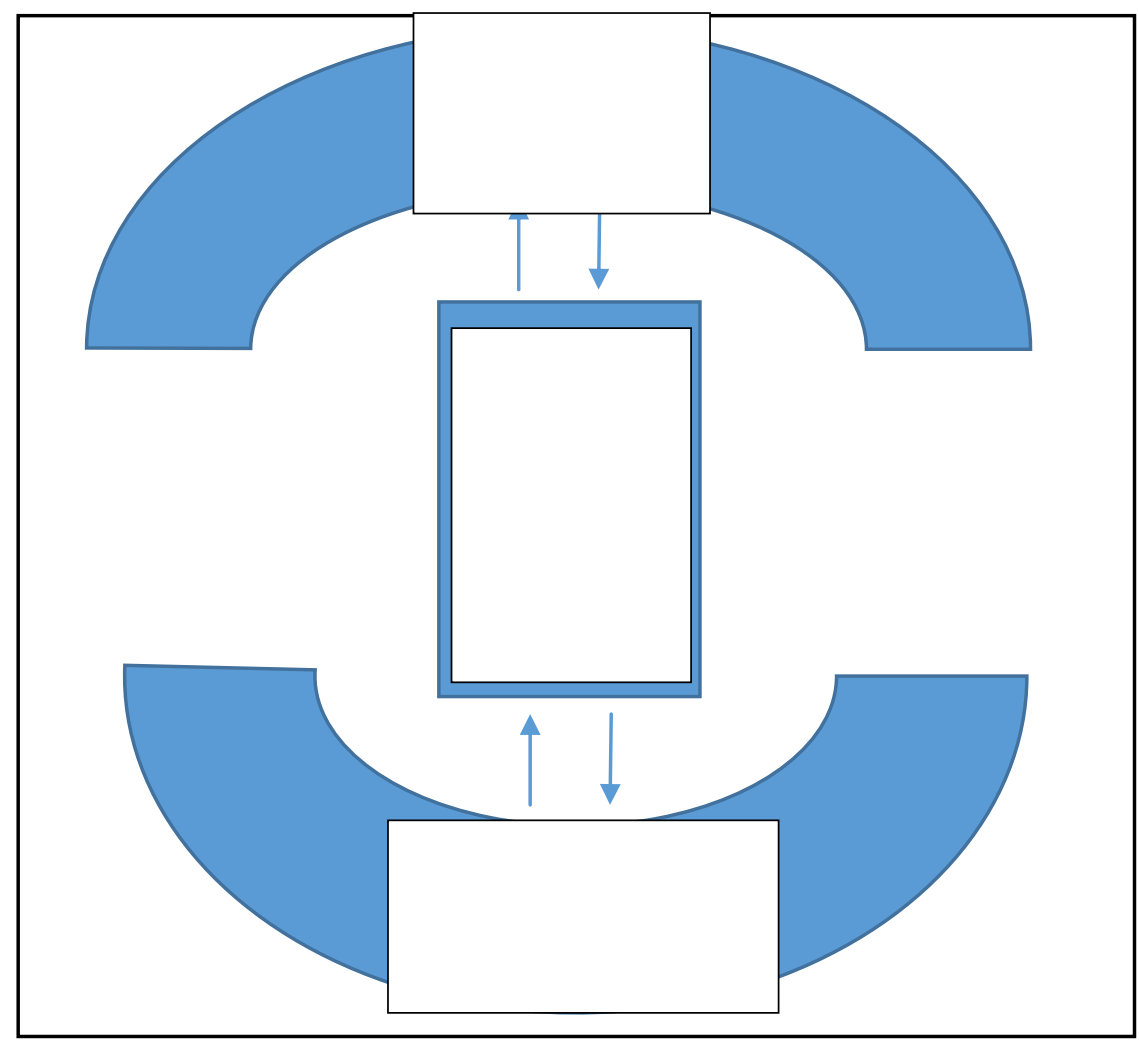

Sustainable state reform requires ownership and on-going support from the state legislature, local government and local school districts. At the basis of state education, reform is teacher knowledge and capacity. According to DarlingHammond (1990), "If policymakers want to change teaching, they must pay attention to teacher knowledge. And if they are to attend to teacher knowledge, they must look beyond curriculum policies to those policies that control teacher education and certification, as well as ongoing professional development, supervision and evaluation (p. 346)." Thus, state legislative efforts must provide funding and expertise for incentivized and ongoing support for school administrators, teachers and school staff centered on meeting the mental health needs of children. Such a support system entails: 1) mental health curriculum centered on student social and emotional learning; 2) recruitment and retention of school site counselors, social workers and mental health personnel; and 3) ongoing SEL professional development of administrators, teachers and staff; and 4) support of the development of school and community collaborative models.

At the local level, attention to enhancing the capacity of teachers, administrators, parents, the public, and community organizations and businesses to understand and participate in SEL reform effortsis required (Goertz, Floden, \&O'Day, 1995). This enables all stakeholders to collectively communicate, with knowledge, about the goals and identified strategies in ensuring student SEL. As a school district model, the Collaborative to Advance Social and Emotional Learning (CASEL) has established social and emotional learning as an essential part of education from preschool 
through high school. It has developed a Social Emotional Learning (SEL) framework based on theory, research and educational best practices as a guide in the selection of research-based prevention programs that address health, substance abuse, violence prevention, sexuality, character, and social skills. (Payton, et.al. 2000).

The SEL competencies include 17 skills and attitudes organized into four groups: awareness of self and others, positive attitudes and values, responsible decision making, and social interaction skills. The program features are deemed as critical to the success of school-based SEL programs with an emphasis on curriculum design, coordination with larger systems, educator preparation and support and program evaluation (Payton, et. al, 2000). Such programs have been instrumental in ensuring students will develop the necessary social and emotional skills needed to improve overall mental health by learning effective coping strategies for everyday stressors, how to effectively communicate and many

One such school district that has implemented the CASEL model is the Anchorage School District (ASD). The ASD deemed SEL as a habit of practice through implementation of SEL skills all day among students, adults, and the entire school community(https://www.asdk12).Through an emphasis on the school climate, direct instruction of SEL skills, and integrating SEL skills throughout the day in all curriculum areas, the district is able to promote SEL skill practice and maximize learning (https://www.asdk12).

\section{Conclusion}

When students feel safe and secure at school, they are more likely to be successful (Brewer, 2017). As a result of the stress, anxiety, bullying and recent school shooting epidemic, students are faced with many adverse experiences in school. While the CDC has partnered with public education to promote the importance of creating resilient youth with effective coping skills, meaning and purpose in life and appropriate social behaviors (2017), further action is needed by federal, state and local governments to support and align those efforts.

The result of a lack of policy protecting and advocating for student mental health, as seen in recent cases of school gun violence perpetrators who received little intervention or support throughout schooling despite the red flags, is of major concern (Golembiewski, 2016). With the nation facing a mental health crisis leading to increased school violence, bullying, suicide, stress and anxiety, the three-tiered model is needed to increase accountability at all levels of the development youth social and emotional skills.

Further research is required to fully understand the impact of social and emotional skill development programs in public schools as well as the process of increased accountability of health care and school personnel in screening and reporting student mental health concerns. The impetus of federal and state financial support for local school district action provides the foundation for further change as the underserved population of students diagnosed with social/emotional trauma continues to surge.

\section{References}

American Civil Liberties Union (2019). Cops and no Counselors: How the lack of school mental health staff is harming students. Retrieved from: https://www.aclu.org/report/cops-and-no-counselors.

Anchorage School District (nd). Social Emotional Learning Anchorage. Retrieved from: https://www.asdk12.org/Page/6643

Association of Supervision and Curriculum Development (2019) http://www.ascd.org/ASCD/pdf/siteASCD/policy/ESSA-Resources_SEL-Funding.pdf

Brewer, S. J. (2017). Addressing youth bullying through the whole child model. Education, (1), 41.

Bitsko, P.R. Blumberg, R.H., SJ, et al. (2013). Centers for Disease Control and Prevention(CDC). Mental health surveillance among children-United States, 2005-2011. MMWRSuppl. 62(2):1-35.

Center for Disease Control and Prevention (2017). Suicide among youth. Retrieved from: https://www.cdc.gov/healthcommunication/toolstemplates/entertainmented/tips/SuicideYouth.html.

Collaborative for Academic, Social, and Emotional Learning (2019). Core SELCompetencies. Retrieved from: https://casel.org/core-competencies/.

Darling-Hammond, L. (1990). Instructional policy into practice: The power of the bottom over the top. Education Evaluation and Policy Analysis 12 (3), 339-47.

DeKruyf, L. 1., Auger, R. W., \& Trice-Black, S. (2013). The role of school counselors in meeting students' mental health needs: examining issues of professional identity. Professional School Counseling, 16(5), 271-282.

Education Commission of the States (2014). States pass diverse slate of mental health legislation in 2013. Retrieved from: https://www.ecs.org/clearinghouse/01/11/29/11129.pdfEducation Commission of the States (2018). Response to information request. Retrieved from:https://www.ecs.org/wp-content/uploads/State-InformationRequest_Student-Mental-Health.pdf 
Education Commission of the States (2019). State Legislation by State. Retrieved from: https://www.ecs.org/state-legislation-by-state/

Forness, S. R., Freeman, S. F. N., Paparella, T., Kauffman, J. M., \& Walker, H. M. (2012). Special education implications of point and cumulative prevalence for children with emotional or behavioral disorders. Journal of Emotional and Behavioral Disorders, 20, 4-18.

Federal Commission on School Safety (2018). Final report of the federal commission on schoolsafety. Retrieved from: https://www2.ed.gov/documents/school-safety/school-safety-report.pdf

Furlong, M., Paige, L. Z., \&Osher, D. (2003). The Safe Schools/Healthy Students (SS/HS) Initiative: lessons learned From Implementing Comprehensive Youth Development Programs. Psychology in the Schools, (5). 447.

Golembiewski, K. (2016). Disparate treatment and lost opportunity: Courts' approach to students with mental health disabilities under the idea. Temple Law Review, 88(3), 473.

Goertz, M.E., Floden, R. E. \&O’Day, J. (1995). Studies of education reform: Systemic reformvolume I: findings and conclusions. U. S. Department of Education, Office of Educational Research and Improvement.

Howell, W. G. (2015). Results of President Obama's Race to the Top. Education Next, Fall2015; 58-66. Retrieved from:https://www.educationnext.org/files/ednext_XV_4_howell.pdf

Jones, D. E., Greenberg, M., \& Crowley, M. (2015). Early Social-Emotional Functioning and Public Health: The Relationship Between Kindergarten Social Competence and Future Wellness. American Journal of Public Health, 105(11), 2283-2290.

Marsh, R. J. (2016). Identifying students with mental health issues: A guide for classroom teachers. Intervention in School and Clinic, 51, 318-322.

Marsh, R. J., Morgan, J. J., Higgins, K., Lark, A., \& Watts, J. T. (2017). Provision of Mental Health Services to Students with Emotional and Behavioral Disorders. Journal Of Disability Policy Studies, 28(2), 90.

Macdonald, H. \&Perez, Z. (2019). 50-state comparison: K-12 school safety. Education Commission of the States. Retrieved from:https://www.ecs.org/50-state-comparison-k-12-school-safety/.

Mental Health America. (2015). Parity or disparity: The state of mental health in America. Alexandria, VA: Author.

Musu-Gillette, L., de Brey, C., McFarland, J., Hussar, W., Sonnenberg, W., and Wilkinson-

Flicker, S. (2017). Status and Trends in the Education of Racial and Ethnic Groups 2017 (NCES 2017-051). U.S. Department of Education, National Center for Education Statistics. Washington, DC. Retrieved from http://nces.ed.gov/pubsearch.

National Association of Secondary School Principals (2018). Mental Health in Middle and HighSchools. Retrieved from: https://www.nassp.org/policy-advocacy-center/nassp-position-statements/promoting-mental-health-inmiddle-level-and-high-schools/

Nelson, C. M., Leone, P. E., \& Rutherford, R. B. (2004). Youth delinquency: Prevention and intervention. In R. B. Rutherford, M. M. Quinn, \& S. R. Mathur (Eds.), Handbook of research in emotional and behavioral disorders (pp. 282-301). New York: Guilford Publications.

Payton,J. W., Wardlaw, D. M., Graczyk, P. A., Bloodworth, M. R.,Tompsett, C. J., \&

Weissberg, R. P. (2000). Social and emotional learning: A framework for promoting mental health and reducing risk behaviors in children and youth. Journal of School Health, 70(5), 179-185.

Spillane, J.P. (1998). State policy and the non-monolithic nature of the local school district: Organizational and professional considerations. American Educational Research Journal, 35, 33-63.

Toma, A. L. (2009). Identifying the Unidentifiable: How Washington's Public Education System Can Aid in the Prevention and Detection of Childhood Mental Illness [comments]. Seattle University Law Review, (1), 255.

Tyler, E. T., Hulkower, R. L \&Kaminski,J. W.(2017). Behavioral health integrationin pediatric primary care: Considerations and opportunities for policymakers, planners, and providers. Milbank Memorial Fund. Retrieved from: https://www.milbank.org/wp-content/uploads/2017/03/MMF_BHI_REPORT_FINAL.pdf

U.S. Department of Education (2015) Every Student Succeeds Act. Retrieved from:https://www.ed.gov/essa

U.S. Department of Education (2015). Office of Elementary and Secondary Education, Office of

State Support, Fundamental Change: Innovation in America's Schools under Race to the Top. Washington D.C. Retrieved from: https://www2.ed.gov/programs/racetothetop/rttfinalrptexecsumm.pdf

U.S. Department of Education (2016). Race to the Top fund. Retrieved from: https://www2.ed.gov/programs/racetothetop/index.html

West Virginia Department of Education (2014). Addressing mental health in school crisis andprevention response. Retrieved from:http://wvde.state.wv.us/counselors/documents/addressingmentalhealth_resource FINAL for Board.pdf 